\title{
Penerapan Oven Roti Berbahan Bakar Gas Dengan Pipa Pemanas di UKM Roti Desa Candiretno Kecamatan Secang, Kabupaten Magelang
}

\author{
Application of Gas-Fueled Oven with Heating Pipe at Bread Small Medium Enterprises \\ (SME) in Candiretno Village, Secang District, Magelang Regency \\ ${ }^{1)}$ Trisma Jaya Saputra, ${ }^{2 *}$ Rany Puspita Dewi, ${ }^{3)}$ Wandi Arnandi \\ ${ }^{1,2,3)}$ Jurusan Teknik Mesin, Fakultas Teknik, Universitas Tidar \\ Jalan Kapten Suparman 39, Magelang 56116 \\ *email: ranypuspita@untidar.ac.id
}

DOI:

Kata kunci: Oven Roti; Bahan Bakar Gas; Produktivitas

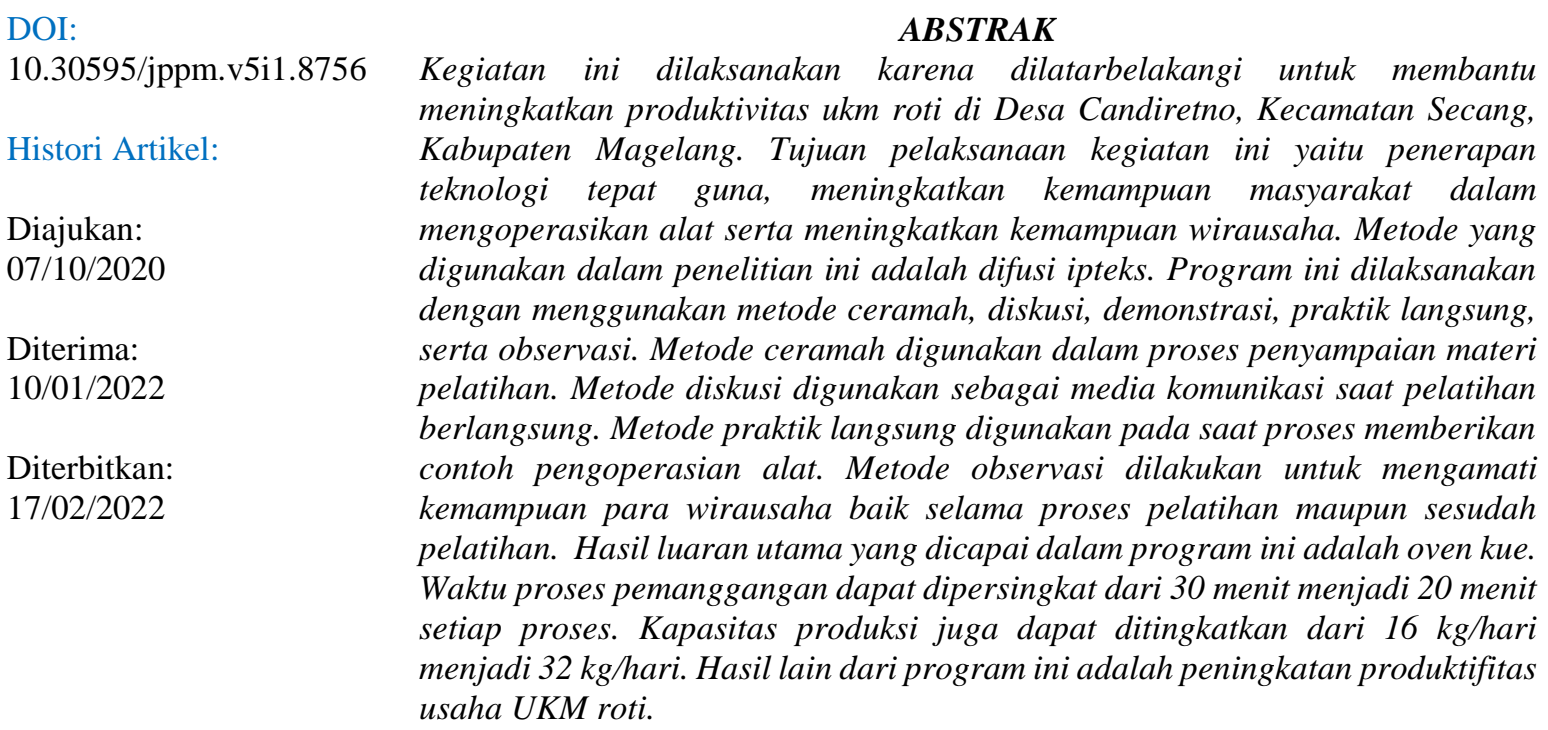

Histori Artikel:

Diajukan:

$07 / 10 / 2020$

Diterima:

$10 / 01 / 2022$

Diterbitkan:

$17 / 02 / 2022$
\end{abstract}

\begin{abstract}
This activity was carried out because it was motivated to help increase the productivity of bread SMEs in Candiretno Village, Secang District, Magelang Regency. The purpose of implementing this activity is the application of appropriate technology, increasing the ability of the community to operate tools and increasing entrepreneurial skills. The method used in this research is science and technology diffusion. This program is implemented using lectures, discussions, demonstrations, hands-on practice, and observation methods. The lecture method is used in the process of delivering training materials. The discussion method is used as a communication medium during the training. The hands-on method used during the process provides examples of tool operation. The observation method is used to observe the abilities of entrepreneurs both during the training process and after training. The main output achieved in this program is a cake oven. The baking process time can be shortened from 30 minutes to 20 minutes per process. Production capacity can also be increased from 16 $\mathrm{kg} /$ day to $32 \mathrm{~kg} /$ day. Another result of this program is an increase in the productivity of the UKM bakery business.
\end{abstract}

Keywords: Bread Oven; Gas Fuel; Productivity 
Trisma Jaya Saputra, Rany Puspita Dewi, Wandi Arnandi

Penerapan Oven Roti Berbahan Bakar Gas Dengan Pipa Pemanas di UKM Roti Desa Candiretno Kecamatan

Secang, Kabupaten Magelang

\section{PENDAHULUAN}

Desa Candiretno merupakan desa di Kecamatan Secang Kabupaten Magelang dengan luas wilayah 302,135 ha berpenduduk 4681 jiwa dengan letak geografis $7.4322 \mathrm{~S}$ dan 110.2523E. Desa Candiretno terdiri dari 9 dusun yaitu dusun Dusun Salam, Dusun STAN, Dusun Tidaran, Dusun Cetokan, Dusun Bengkung, Dusun Manggis, Dusun Weru, Dusun Pongangan dan Dusun Rejosari. Transportasi ke desa ini mudah untuk dilalui karena merupakan jalur alternatif YogyakartaSemarang.

Penduduk Dusun Tidaran Desa Candiretno berprofesi sebagai petani, pedagang dan wirausaha. Wirausaha yang dilakukan berupa makanan seperti roti dan kue. Wirausaha roti yang dirintis oleh ibu Tarwiyah telah beroperasi sejak tahun 2000, produk yang dihasilkan adalah roti dan bolu, namun untuk bolu dihentikan dikarenakan hasil pengovenan yang kurang baik yaitu tingkat kematangan pada setiap sisi tidak merata, untuk roti masih berproduksi sampai saat ini dan menghasilkan rata-rata $10-15 \mathrm{~kg} / \mathrm{hari}$ dengan harga jual Rp.30.000,-/kg. Hasil produksi ini langsung diambil oleh pengepul dan dipasarkan di daerah Secang dan sekitarnya, karena keterbatasan produksi sehingga belum dapat memenuhi permintaan pasar.

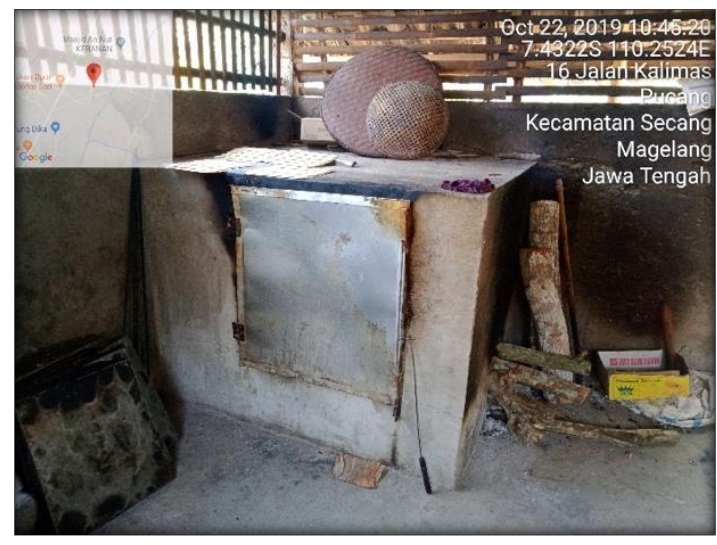

Gambar 1. Oven tradisional

Permasalahan yang terjadi pada proses produksi UKM roti saat ini adalah pada proses pengovenan (Gambar 2). Temperatur pengovenan berkisar antara $160-200^{\circ} \mathrm{C}$ dan temperatur ini harus selalu terjaga. Dengan pengovenan yang baik dapat meningkatkan produksi dan memproduksi kembali bolu yang telah lama terhenti. Proses pengovenan roti yang dilakukan dengan pengovenan tradisional yang terbuat dari beton berukuran $1 \mathrm{~m}^{3}$ tanpa menggunakan kontrol temperatur dan pengatur panas yang dihasilkan dari nyala pembakaran. Hal ini menyebabkan ketidakstabilan panas yang dihasilkan. Bahan bakar yang digunakan pada oven tradisional adalah kayu bakar. Pengovenan dilakukan selama 30 menit untuk sekali proses.

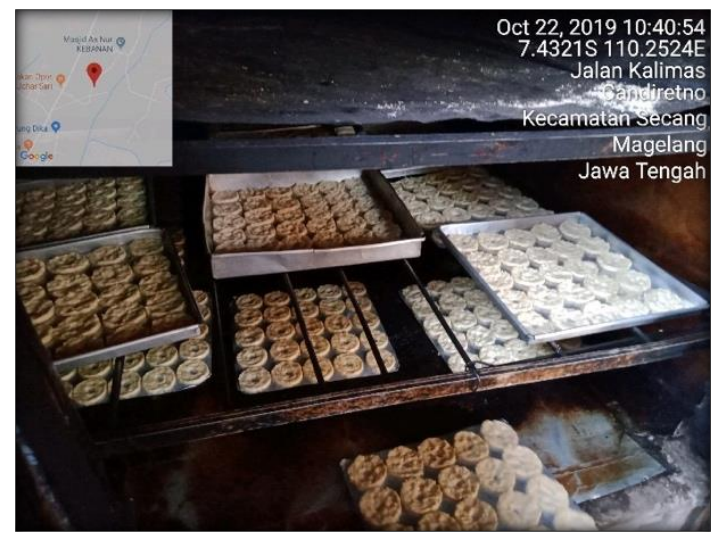

Gambar 2. Proses pengovenan

Oleh karena itu, UKM roti membutuhkan alat bantu dalam proses produksi guna meningkatkan kapasitas produksi, salah satunya melalui penerapan teknologi tepat guna berupa oven roti berbahan bakar gas. Mesin oven pengering roti sudah pernah dirancang oleh Fadli (2017), oven pengering yang dirancang berkapasitas $5 \mathrm{~kg}$ untuk sekali proses penggovenan, waktu rata-rata yang dibutuhkan untuk memanggang $2,5 \mathrm{~kg}$ roti adalah 25 menit. Oven kue juga pernah dirancang oleh Naim (2019), oven yang dibuat dioperasikan dengan 2 sumber panas yaitu listrik dan gas, gas sebagai alternatif sumber panas. Suhu pemanggangan elemen pemanas maksimal $120^{\circ} \mathrm{C}$. Diharapkan dengan penerapan oven roti pada UKM roti dapat meningkatkan kapasitas produksi roti dan meningkatkan kesejahteraan masyarakat Dusun Tidaran, Desa Candiretno, Kecamatan Secang, Kabupaten Magelang.

Berdasarkan analisis situasi, terdapat permasalahan utama warga masyarakat Dusun Tidaran diantaranya yaitu: 
Trisma Jaya Saputra, Rany Puspita Dewi, Wandi Arnandi

Penerapan Oven Roti Berbahan Bakar Gas Dengan Pipa Pemanas di UKM Roti Desa Candiretno Kecamatan Secang, Kabupaten Magelang

1) Proses produksi (proses pemanggangangan) yang masih dilakukan secara manual

2) Minimnya pengetahuan masyarakat mengenai oven roti berbahan bakar gas

Target luaran dalam penerapan program ini bagi mitra yaitu berupa produk oven roti, meningkatnya kapasitas produksi roti, dan meningkatkan pengetahuan masyarakat terkait alat oven roti berbahan bakar gas. Melalui penerapan alat oven roti dapat meningkatkan kapasitas produksi roti minimal hingga $50 \%$.

\section{METODE}

Metode pelaksanaan kegiatan terbagi menjadi enam tahap. Tahap pertama adalah survey pendahuluan, untuk mendapatkan gambaran nyata di lapangan tentang permasalahan yang dihadapi oleh kelompok mitra. Kegiatan dilakukan dengan cara diskusi langsung dengan UKM roti Dusun Tidaran. Tahap kedua adalah analisis kebutuhan, untuk menganalisis kebutuhan yang akan menjadi solusi dari permasalahan tim mitra. Dengan analisis kebutuhan, tim mempunyai gambaran tentang solusi yang akan ditawarkan. Tahap ketiga adalah perancangan mesin. Tahap keempat adalah pembuatan alat yang dilaksanakan di laboratorium Teknik Mesin, Universitas Tidar. Tahap kelima adalah uji coba dan penerapan alat. Tahap terakhir adalah monitoring dan evaluasi penerapan alat oven roti di Dusun Tidaran, Desa Candiretno. Pada Tahap ini diperoleh gambaran nyata pemanfaatan alat oven roti di UKM roti, Dusun Tidaran, Desa Candiretno.

\section{HASIL DAN PEMBAHASAN}

Hasil dari kegiatan ini berupa alat oven roti. Pembuatan dan pengujian alat oven roti memerlukan waktu kurang lebih 1 bulan. Desain alat oven roti yang dibuat ditunjukkan pada Gambar 3. dan alat oven roti berbahan bakar gas ditunjukkan pada Gambar 4. Spesifikasi alat ditunjukkan pada Tabel 1.
Tabel 1. Spesifikasi alat

\begin{tabular}{|c|c|c|c|}
\hline NO & BAGIAN & DIMENSI & BAHAN \\
\hline \multirow[t]{4}{*}{1} & Oven & $\begin{array}{l}550 \times 550 \\
\times 1005 \\
\mathrm{~mm}\end{array}$ & \\
\hline & Rangka & & $\begin{array}{l}\text { Besi } 30 \mathrm{x} \\
30 \mathrm{~mm}\end{array}$ \\
\hline & Dinding & & $\begin{array}{l}\text { Aluminium } \\
1 \mathrm{~mm}\end{array}$ \\
\hline & $\begin{array}{l}\text { Isplator } \\
\text { panas }\end{array}$ & & $\begin{array}{l}\text { Aluminium } \\
\text { foil }\end{array}$ \\
\hline 2 & $\begin{array}{l}\text { Bahan } \\
\text { bakar }\end{array}$ & $3 \mathrm{~kg}$ & LPJ \\
\hline 3 & Tungku & $\begin{array}{l}200 \times 300 \\
\text { mm } \\
\text { (spiral) }\end{array}$ & besi \\
\hline 4 & $\begin{array}{l}\text { Ruang } \\
\text { pemangan }\end{array}$ & $\begin{array}{l}400 \times 400 \\
\text { mm (2 } \\
\text { ruang) }\end{array}$ & Aluminium \\
\hline 5 & Nampan & $\begin{array}{l}400 \times 400 \\
\mathrm{~mm}(6 \\
\text { buah) }\end{array}$ & Aluminium \\
\hline 6 & Kapasitas & $2 \times 5 \mathrm{~kg}$ & \\
\hline 7 & $\begin{array}{l}\text { Alat } \\
\text { pengukur } \\
\text { temperatur }\end{array}$ & & Digital \\
\hline
\end{tabular}

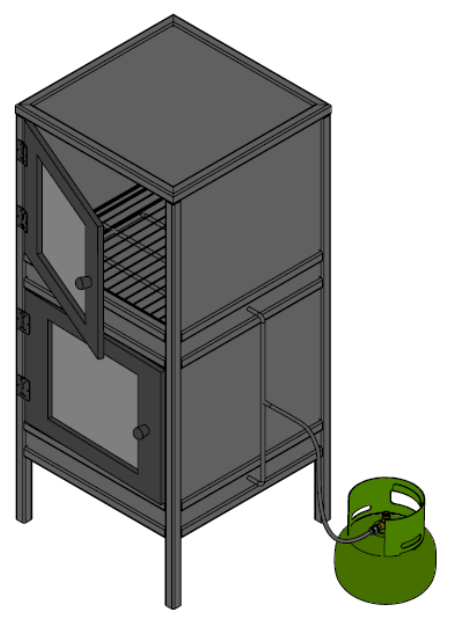

Gambar 3. Desain oven roti 


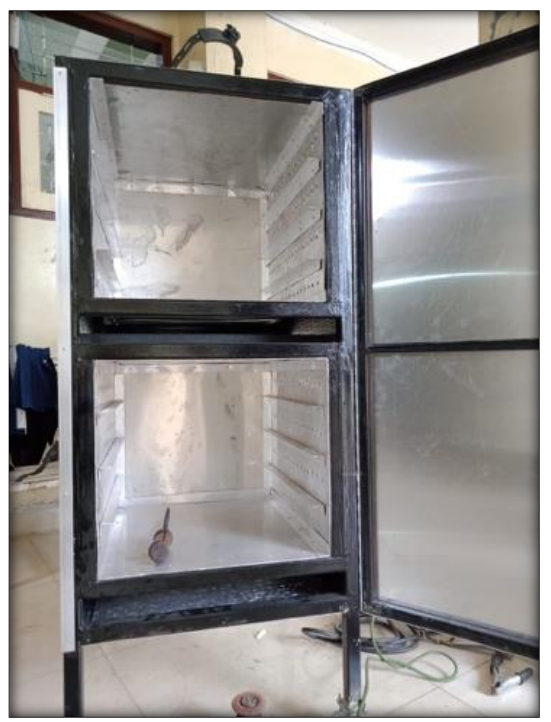

Gambar 4. Oven roti berbahan bakar gas

Hasil lain dari kegiatan pengabdian kepada masyarakat ini adalah meningkatnya pengetahuan masyarakat dalam menggunakan alat oven roti di lingkungan Dusun Tidaran. Masyarakat yang sebelumnya hanya mengetahui metode pemanggangan roti secara manual, saat ini sudah dapat menggunakan alat oven roti yang lebih efektif dengan menggunakan bahan bakar gas

\section{SIMPULAN}

Alat oven roti yang dibuat telah memberikan manfaat bagi warga masyarakat di Dusun Gentan untuk lebih meningkatkan produktivitas warga yang berprofesi sebagai pengusaha UKM roti. Tahap selanjutnya adalah mengukur efektifitas penggunaan alat oven roti dalam meningkatkan produktivitas UKM roti.

\section{DAFTAR PUSTAKA}

Astuti, R.M. (2015). Pengaruh Penggunaan Suhu Pengovenan Terhadap Kualitas Kue Pelox Manis Dilihat Dari Aspek Warna Kulit, Rasa, dan Tekstur. Teknobuga Vol 2. No.2.

Fadli, M.I., Alfa'izin, H.M., dan Siswadi. (2017). Perancangan Alat Teknologi Tepat Guna Mesin Oven Pengering Roti. Jurnal Teknologi Fakultas Teknik, Universitas Wijaya Putra.
LPPM-PMP Universitas Tidar. (2018). Panduan Pelaksanaan Pengabdian Kepada Masyarakat Universitas Tidar, Universitas Tidar. Magelang.

Naim, M., Asmauna, A., Surika, I., dan Mangkali, M.T. (2019). Rancang Bangun Oven Kue Dengan Dua Sumber Panas. Dinamika : Jurnal Ilmiah Teknik Mesin Vo. 10, No.2.

Taufan, A., Novrinaldi., dan Hanifah, U. (2013). Rancang Bangun dan Pengujian Tungku Berbahan Bakar Gas Untuk Industri Tahu Tradisional Berbasis Produk Bersih. Agritech Vol.33, No.4.

Tresia, N., Elida., dan Faridah, A. (2017). Pengaruh Suhu Oven Dalam Pemanggangan Terhadap Kualitas Kue Sus. Program Studi Pendidikan Kesejahteraan Keluarga. Universitas Negeri Padang.

Wiryosumanto, H., dan Okumura, T. (2008). Teknologi Pengelasan Logam. Jakarta: Pradnya Paramita. 